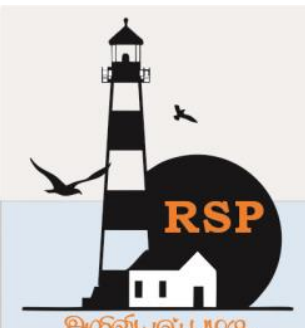

INTERNATIONAL RESEARCH JOURNAL ON ADVANCED SCIENCE HUB

\title{
AgriGeek - A Mobile Application based on Smart Farming Hybrid Monitoring System
}

Karthikraj $H^{1}$, Kavinraja A. $S^{2}$, Kishore Karthi $V^{3}$, Sree Poornalinga $K^{4}$

${ }^{1,2,3}$ UG Scholar, Department of Computer Science and Engineering, SNS College of Technology, Coimbatore, India.

${ }^{4}$ Assistant Professor Department of Information Technology, SNS College of Technology, Coimbatore, India.

hkarthikraj01@gmail.com ${ }^{1}$, kavinraja123@gmail.com², kishorekarthi444@gmail.com ${ }^{3}$, ksplmay@gmail.com ${ }^{4}$

\begin{abstract}
In olden days our ancestors followed an effective seasonal method for traditional agriculture. But due to changes in the climatic conditions and natural disasters, the seasonal method is not working effectively nowadays. Internet of Things is trying to do smart farming and it's becoming a trend now. But, research shows that the smart farming is degrading the quality of farming and agriculture. In order to provide a quality farming, we propose a new dynamic clustering and data gathering system for harnessing the IoT in agriculture. This paper provides a new IoT based Smart Farming using Hybrid Monitoring System called the AgriGeek, supported with a mobile interfaced application which improves the efficiency of smart farming. AgriGeek helps the farmers to remotely monitor and control their farmland, harvested crops and farming equipment through mobile phones. A well-connected farming network has been created for knowledge sharing among the farmers by measuring agri-related information like temperature, humidity, soil PH, soil nutrition levels and water level, which helps us to do the traditional agriculture via smart farming.
\end{abstract}

Keywords: Agriculture, Hybrid Monitoring System, Internet of Things, Knowledge sharing, Smart Farming.

\section{Introduction}

Agriculture is the only way for food production. Traditional agriculture is the precise way for producing effective and healthy foods, which was practiced based on the seasonal method for every crop. Ancestral Farmers followed traditional way of agriculture farming for varieties of crops. But in current days, seasonal methods of agriculture is not possible due to global warming and changes in climatic conditions and it is considered to be one of the prominent drawback for practicing traditional agriculture. Since the practice of agriculture has been decreased, retaining the nutritious food has become tedious. In order to bring the quality of agriculture back and fix the problem, smart farming using technologies comes into play. A new revolution of agriculture has begun called the hybrid agriculture which combines the technology and manual support for farming. Many invention in the field of agriculture has been evolved and made into practice, but still the technology doesn't follow the traditional way of doing the farming. The timeliness and fixation of automation makes the farming process to malfunction most of the time. Irregular and improper irrigation and farming is being done using the automated farming equipment 
which leads to wastage of cropping and foods. This kind of wrong way of doing agriculture results in forming many side effects from foods such as vitamins and calcium deficiency. So, our goal is to bring back the traditional agriculture via smart farming that is creating a technology that would bring back the quality of traditional farming back. This can be done with the help of internet of things (IoT). Smart farming method is becoming trend in nowadays. In this paper, we propose a dynamic clustering and data gathering system for `harnessing the IoT in agriculture to provide quality farming. A new IoT based smart farming based on hybrid monitoring system interfaced with an android application called the AgriGeek. AgriGeek is a data analytics IoT based app which will have the data's based on the traditional agriculture, and using this app for monitoring the land will be under surveillance. The proposed hybrid monitoring system is a package of sensors technology, big data analytics and android application system. AgriGeek helps the farmers to remotely monitor and control their farm land, harvested crops and farming equipment through smart phones. This application provides instructions to follow traditional agriculture in this scenario by giving accurate information about temperature, humidity, soil moisture level, water level and so on. Retaining the traditional agriculture via smart farming helps us to grow and produce healthy foods.

\section{Problem Identification}

\subsection{Aim of the paper}

The aim of the paper is to identify the problems in agriculture field and rectifying it. We propose a new monitoring system based on IoT integrated with sensors and cloud technology. We developed a new application called AgriGeek which aims to clear the problems and instruct the system to do the traditional farming agriculture.

\subsection{ISSUES}

The traditional agricultural practices are not possible because of the climatic changes such as global warming and natural disasters such as flood and heavy rain. The field of agricultural is facing a huge defies that is to produce more crops using fewer resources, despite the fact reducing any negative effects on society and the environment.
Smart Farming and Big Data are considered to be a solution to solve this problem. Another drawbacks in agricultural field is that; there is no proper guidance for practicing the right way of farming, there is no proper maintenance of the cultivated crops. To overcome these flaws The Smart Farming was introduced. As per the todays scenario the smart farming also does not work more efficiently.

\section{Proposed system}

We proposed a hybrid monitoring system that integrates the sensors and cloud technology together for work along with the IoT based android application. Figure 1 shows the working design of our proposed system interfaced with IoT application called AgriGeek. This proposed system has been divided into three divisions, namely sensor technology, big data analytics and android application system which process together to solve the problems in agriculture field via smart farming.

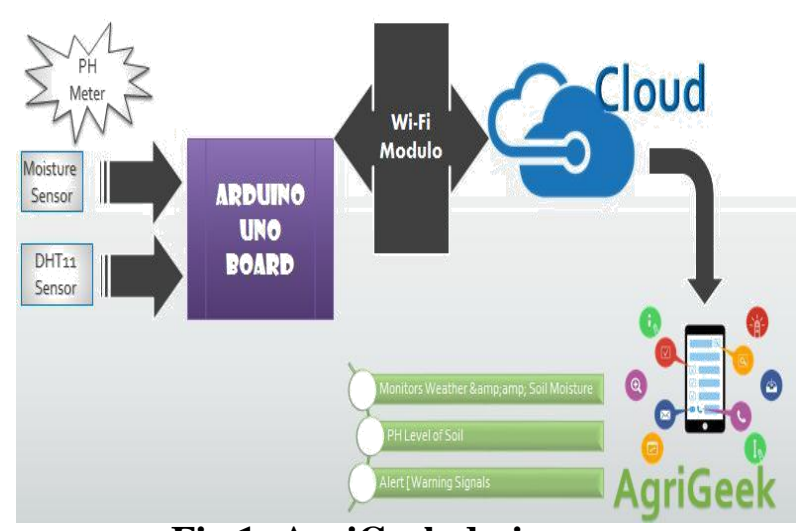

Fig 1: AgriGeek design

\subsection{Sensor technology}

Sensors are used to sense the objects based on its characteristics, this division of the system is major in the process farming, which deals with the soil, moisture and water level. Varies kinds of sensors were used in the farm land for monitoring the land status or to measure the level of moisture content. Sensors like DHT11, Soil moisture and PIR are used in the monitoring system.

\subsection{Big data analytics}

For the Predictive purpose, the analytics of collected data and monitored data must be analysed toughly, which can be used for making smarter 
decisions during real-time farming. Data on weather, soil and air quality and crop maturity availability, the prediction is made. Big data is expected to play an important role in precision agriculture for managing real-time data analysis with considerable streaming of data. The efficiency of data analysis and throughput would be a challenge with the massive increase in size of big data. The unstructured streaming of data established from diverse agricultural sources would contain multiple dimensions.

\subsubsection{Data collection:}

Sensor provides the raw information taken in the farm land through the Wi-Fi modulo (ESP2866) and then data collection process is done using cloud technology.

\subsubsection{Data analytics:}

It is used to process the huge set of information collected from the agriculture field and transfers the required information to the application.

\subsection{Android app system:}

This is the final and foremost sector of the AgriGeek. It is used to display the output of this process and instruct the user to do proper method of agriculture. This sector remotely monitors and control the agriculture field as user needs.

\section{Methodology}

Data analytics plays a vital role in smart farming via internet of things in most efficient way. Sensor technology, big data, android application system are the key methodologies used in proposed technology called AgriGeek. A clear and deep theoretical study of each methodology has provided below.

\subsection{Sensor technology}

A combination of DHT11, Soil Moisture, PIR sensors are used in this process of monitoring system. Fig 2. Shows an idea of fixing sensors around the surrounding.

\subsubsection{DHT11 Sensor:}

Digital Humidity and Temperature (DHT11) sensor which used is measure the temperature and humidity. It is used to measure the temperature and humidity of the cultivation land. This information is used to predict the crop to cultivate in farm land. This sensor gives the real life and accurate values to do proper agriculture. It predicts the changes in climatic conditions and alerts by the use of application.

\subsubsection{Soil Moisture Sensor}

Soil moisture sensor aids to evaluate the moisture content of the soil. It gives the information about the water content and moisture level of the farm land where the cultivation of crop is done. And gives results as the suitable crop to be cultivated for predicted moisture content. It monitors the water content of the farm land and it gives alert when the water content of the soil increased or decreased through the mobile application.

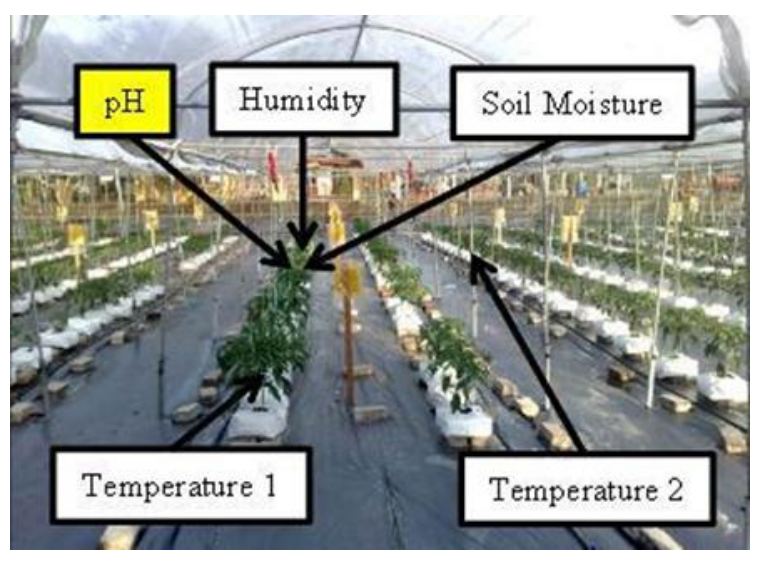

Figure 2: sensor processing

\subsubsection{Passive infrared sensor:}

A PIR based motion detector is used to sense moment of insects, animals and other objects. It can be used to protect the farm land from insects and animals. When the affection of insects increased, it gives an alert and provides the information about the insect and insecticide to be used for protection.

\subsection{Big data Analytics:}

Big data is diverse, complex whole scale which requires new architecture, techniques, analytics to manage it and extract value and hidden knowledge from it. Big data is used filter the required from collection of huge set of data by data processing. This is used to collect the huge set of information from sensors through $\mathrm{Wi}-\mathrm{Fi}$ modulo and process those data and provides the required information to application. This plays an esssential role in conveying information about the farm land to android application. Process of the big data analytics is provided in Figure3.

\subsection{Android application system:}

Android is a mobile operating system initiated by Google. It is used by smartphones and tablets. The android operating system (OS) is based on the Linux kernel. Android is an open source, android is specially developed for application systems. An 
application called AgriGeek is based on smart farming and hybrid monitoring system. The monitoring and controlling process are done using the application. This application displays the results of sensor predictions in farm land for cultivations. The alerts about the water content problems and climatic condition changes are shown by this application. It gives the instructions for maintaining and cultivating the farmland in traditional agricultural method.

\section{Conclusion:}

Surveilling environmental factors is the most important factor to improve the yield of the efficient crops. AgriGeek is architected and designed to improve the efficiency of agriculture, build a well-connected farming network and create a knowledge sharing platforms for farmers by measuring agriculture related information like temperature, humidity, soil $\mathrm{pH}$, soil nutrition level, water level, etc.., with the help of cloud technology, big data analysis and android application system.

\section{Reference:}

[1] Ji-chun Zhao, Jun feng Zhang, Yu Feng, Jainxin Guo, "The Study and Application of the IoT Technology in Agriculture", IEEE, 2010.

[2] Adams, M.L., Cook, S. \& Corner, R. , "Managing Uncertainty in Site-Specific Management: What is the Best Model?" Precision Agriculture. 2, 39-54, 2000.

[3] Wang, N., Zhang, N. \& Wang, M., "Wireless Sensors in Agriculture and Food Industry-Recent Development and Future Perspective, Review", Computers and Electronics in Agriculture, 50, 114, 2006.

[4] C. Alippi, R. Camplani, C. Galperti and M. Roveri, "A Robust, Adaptive, Solar-Powered WSN Framework for Aquatic Environmental Monitoring," in IEEE Sensors Journal, Vol. 11, No. 1, pp. 45-55, 2011.

[5] Robinson, D. A., C. S. Campbell, J. W. Hopmans, B. K. Hornbuckle, S. B. Jones, R. Knight, F. Ogden, J. Selker, and O. Wendroth , "Soil moisture measurements for ecological and hydrological watershed scale observatories: A review”, Vadose Zone J., 7, 358 - 389, 2008.

[6] Han, P.; Dong, D.; Zhao, X.; Jiao, L.; Lang, Y. A smartphone-based soil color sensor: For soil type classification. Comput. Electron. Agric. 2016, 123,
232-241.

[7] Mohapatra, A.G.; Lenka, S.K. Neural network pattern classification and weather dependent fuzzy logic model for irrigation control in WSN based precision agriculture. Procedia Comput. Sci. 2016, 78, 499-506.

[8] Rault, T.; Bouabdallah, A.; Challal, Y. Energy efficiency in wireless sensor networks: A top-down survey. Comput. Netw. 2014, 67, 104-122. 